\title{
Targeting caveolin-1 deficiency in bone marrow derived cells: a new therapeutic window for fibrotic diseases?
}

\author{
Eleonora Cianci $^{1,2}$ and Antonio Recchiuti ${ }^{2,3 *}$ \\ ${ }^{1}$ Department of Medicine and Aging Science, G. d'Annunzio University, Chieti, Italy \\ ${ }^{2}$ Center of Excellence on Aging, G. d'Annunzio University, Chieti, Italy \\ ${ }^{3}$ Department of Experimental and Clinical Science, G. d'Annunzio University, Chieti, Italy \\ *Correspondence: a.recchiuti@unich.it \\ Edited by: \\ Lynne Anne Murray, Medlmmune Ltd., UK \\ Reviewed by: \\ Stephen John Wilson, University of California, San Francisco, USA \\ Lynne Anne Murray, Medlmmune Ltd., UK
}

Keywords: Inflammation, fibrocytes, cell migration, Pharmacology, cytokines/chemokines, cell differentiation, resolution of inflammation

\section{A commentary on}

Caveolin-1 regulates chemokine receptor 5-mediated contribution of bone marrow-derived cells to dermal fibrosis by Lee, R., Perry, B., Heywood, J., Reese, C., Bonner, M., Hatfield, C. et al. (2014). Front. Pharmacol. 5:140. doi: 10.3389/fphar.2014. 00140

Tissue repair is an essential component of wound healing and resolution of inflammation that, when uncontrolled, can lead to excessive scarring and organ failure (Majno, 1991). Indeed, exaggerated and persistent extracellular matrix (ECM) deposition in tissues is the hallmark of many pathologies linked to nonresolving inflammation, such as asthma, chronic obstructive pulmonary disease, and atherosclerosis (Nathan and Ding, 2010; Serhan et al., 2010; Tabas and Glass, 2013). Systemic fibrosis, also called scleroderma (SSc) is a rare, often idiopathic, autoimmune disease in which a chronic inflammation leads to diffuse fibrosis in several organs, mainly skin, lungs, kidneys, eyes, heart, liver (Shah and Wigley, 2014). Despite considerable advances, this pathology, which affects several million of individuals worldwide, is still without a specific and effective therapy (Canady et al., 2013)

The ancient dogma that fibrosis originates from hyperactivation or deregulation of tissue resident fibroblasts by the local milieu of cytokines and growth factors has been challenged by accruing evidence signifying now that many cells can contribute to the pathogenesis of fibrosis. These include bone marrow (BM)derived monocytes that can differentiate into "fibrocytes," i.e., collagen-producing leukocytes (Bucala et al., 1994), that can not only release ECM proteins, but also secrete pro-inflammatory cytokines, chemokines, and growth factors that amplify the pro-fibrotic process in a vicious circle (Metz, 2003). Hence, bone marrow derived fibrocytes represent an important cellular target in SSC and other chronic diseases.

It is well documented that in fibrotic diseases caveolin (Cav)-1 expression is profoundly reduced in fibroblast and monocytes. Cav-1 is a master regulator of several kinases downstream of growth factor, chemokines, and cytokine receptors, as well as many other cellular functions [e.g., ECM adhesion, lipid transport, and membrane traffic (Boscher and Nabi, 2012)]. Lack of Cav-1 in SSc patients and nullified mice results in collagen overexpression and monocyte hypermigration. Therefore, in recent years, Cav-1 has been object of intense scrutiny as possible molecular pharmaceutical target to treat SSc and other fibrotic diseases (Tourkina et al., 2008).

In this Research Topic of Frontiers in Pharmacology named The Cell Types of Fibrosis, Lee et al. (2014) demonstrate that treatment with a Cav-1 scaffolding domain peptide (CSD) spanning amino acids $82-101$ of the full protein inhibits dermal fibrosis and lipodystrophy in a mouse model of bleomycin-induced fibrosis that closely mimic the histopathology of skin observed in clinical situations of SSc. Namely, the authors demonstrate that CSD significantly reduced accumulation in skin and dermis of SSc mice of chemokine receptor (CCR) 5 positive monocytes and fibrocytes, which are increased in fibrotic lesions of SSc mice and SSc patients, and ameliorated the clinical signs of skin fibrosis. Moreover, CSD treatment reduced migration of SSc monocytes toward CCR5 ligands and diminished receptor expression in SSc monocytes.

These results represent a step forward toward the exploitation of Cav-1 directed therapeutics for the treatment of SSc and open the road for further studies aimed at establishing the molecular mechanisms by which CSD protects from fibrosis. For instance, additional studies could investigate whether CSD acts by re-establishing the correct turnover of CCR5 upon engagement to its ligands. Or, whether CSD modifies the phenotype of BM-derived fibrocytes (e.g., reducing their capability of secreting ECM components and other pro-fibrotic mediators). Furthermore, the study of Lee and colleagues provides proof of concept for testing CSD for the treatment of fibrosis in different pathologies characterized by a deregulation of monocyte plasticity and functions. For example, in atherosclerotic plaque monocyte-macrophages can either differentiate into lipid rich "foam cells" and secrete factors that sustain atheroma formation or can be stimulated to promote resolution (Moore and Tabas, 2011; Randolph, 2014). Likewise, macrophages 
accumulate in obese fat tissues (Weisberg et al., 2003) and have a distinct signature of lipid mediators, cytokines, and adipokines in obesity that can be skewed to limit the inflammatory tone (Hellmann et al., 2011; Titos et al., 2011). Finally, lung fibrosis is a hallmark of chronic respiratory pathologies such as asthma, chronic obstructive pulmonary disease, and cystic fibrosis in which airways are repeatedly exposed to insults (Levy and Serhan, 2014). Whether Cav-1 deficiency and increased infiltration of BM-derived fibrocytes also occur in these and other illnesses, and whether CSD treatment proves therapeutically effective is of paramount interest.

\section{REFERENCES}

Boscher, C., and Nabi, I. R. (2012). Caveolin-1: role in cell signaling. Caveolins Caveolae Springer 29-50. doi: 10.1007/978-1-4614-1222-9_3

Bucala, R., Spiegel, L. A., Chesney, J., Hogan, M., and Cerami, A. (1994). Circulating fibrocytes define a new leukocyte subpopulation that mediates tissue repair. Mol. Med. 1, 71-81.

Canady, J., Karrer, S., Fleck, M., and Bosserhoff, A. K. (2013). Fibrosing connective tissue disorders of the skin: molecular similarities and distinctions. J. Dermatol. Sci. 70, 151-158. doi: 10.1016/j.jdermsci.2013.03.005

Hellmann, J., Tang, Y., Kosuri, M., Bhatnagar, A., and Spite, M. (2011). Resolvin D1 decreases adipose tissue macrophage accumulation and improves insulin sensitivity in obese-diabetic mice. FASEB J. 25, 2399-2407. doi: 10.1096/fj.10-178657

Lee, R., Perry, B., Heywood, J., Reese, C., Bonner, M., Hatfield, C. M., et al. (2014). Caveolin-1 regulates chemokine receptor 5-mediated contribution of bone marrow-derived cells to dermal fibrosis. Front. Pharmacol. 5:140. doi: 10.3389/fphar.2014. 00140

Levy, B. D., and Serhan, C. N. (2014). Resolution of acute inflammation in the lung. Annu. Rev. Physiol. 76, 467-492. doi: 10.1146/annurevphysiol-021113-170408

Majno, G. (1991). The Healing Hand: Man and Wound in the Ancient World. Cambridge, MA: Harvard University Press.

Metz, C. N. (2003). Fibrocytes: a unique cell population implicated in wound healing. Cell. Mol. Life Sci. 60, 1342-1350. doi: 10.1007/s00018-0032328-0

Moore, K. J., and Tabas, I. (2011). Macrophages in the pathogenesis of atherosclerosis. Cell 145, 341-355. doi: 10.1016/j.cell.2011.04.005

Nathan, C., and Ding, A. (2010). Nonresolving inflammation. Cell 140, 871-882. doi: 10.1016/j. cell.2010.02.029

Randolph, G. J. (2014). Mechanisms that regulate macrophage burden in atherosclerosis. Circ. Res. 114, 1757-1771. doi: 10.1161/CIRCRESAHA.114. 301174

Serhan, C. N., Ward, P. A., and Gilroy, D. W. (2010). Fundamentals of Inflammation. New York, NY: Cambridge University Press. doi: 10.1017/CBO97 81139195737

Shah, A. A., and Wigley, F. M. (2014). My approach to the treatment of scleroderma. Mayo Clin. Proc. 88, 377-393. doi: 10.1016/j.mayocp. 2013. 01.018

Tabas, I., and Glass, C. K. (2013). Anti-inflammatory therapy in chronic disease: challenges and opportunities. Science 339, 166-172. doi: 10.1126/science. 1230720

Titos, E., Rius, B., González-Périz, A., López-Vicario, C., Morán-Salvador, E., Martínez-Clemente, M., et al. (2011). Resolvin D1 and its precursor docosahexaenoic acid promote resolution of adipose tissue inflammation by eliciting macrophage polarization toward an M2-like phenotype. J. Immunol. 187, 5408-5418. doi: 10.4049/jimmunol.1100225

Tourkina, E., Richard, M., Gööz, P., Bonner, M., Pannu, J., Harley, R., et al. (2008). Antifibrotic properties of caveolin-1 scaffolding domain in vitro and in vivo. Am. J. Physiol. Lung Cell. Mol. Physiol. 294, L843-L861. doi: 10.1152/ajplung. 00295.2007

Weisberg, S. P., McCann, D., Desai, M., Rosenbaum, M., Leibel, R. L., and Ferrante, A. W. Jr. (2003). Obesity is associated with macrophage accumulation in adipose tissue. J. Clin. Invest. 112, 1796-1808. doi: 10.1172/JCI2003 19246

Conflict of Interest Statement: The authors declare that the research was conducted in the absence of any commercial or financial relationships that could be construed as a potential conflict of interest.

Received: 01 July 2014; paper pending published: 17 July 2014; accepted: 01 August 2014; published online: 22 August 2014.

Citation: Cianci E and Recchiuti A (2014) Targeting caveolin-1 deficiency in bone marrow derived cells: a new therapeutic window for fibrotic diseases? Front. Pharmacol. 5:193. doi: 10.3389/fphar.2014.00193

This article was submitted to Inflammation Pharmacology, a section of the journal Frontiers in Pharmacology.

Copyright (c) 2014 Cianci and Recchiuti. This is an open-access article distributed under the terms of the Creative Commons Attribution License (CC BY). The use, distribution or reproduction in other forums is permitted, provided the original author(s) or licensor are credited and that the original publication in this journal is cited, in accordance with accepted academic practice. No use, distribution or reproduction is permitted which does not comply with these terms. 